\title{
Estudo comparativo sobre a evolução semântica dos termos mariage e casamento nas legislações francesa e brasileira do século $\mathrm{XVI}$ ao XIX
}

\section{A comparative study on semantic evolution of the terms mariage and casamento in the French and Brazilian legislations from the XVI to XIX centuries}

Beatriz Curti-Contessoto* Lidia Almeida Barros*

Resumo: Neste trabalho, objetivamos verificar, à luz de uma perspectiva diacrônicocomparada, a evolução semântico-conceitual dos termos mariage e casamento no domínio do Direito a partir do momento em que ocorreu a primeira regulamentação sobre os casamentos oficiais na França (1563) e no Brasil (1827) até o aparecimento inédito do casamento civil e laico nas legislações francesa e brasileira em 1791 e 1890, respectivamente. Pretendemos ainda relacionar essa evolução a aspectos socioculturais e históricos de cada país. Para tanto, fundamentamo-nos nos pressupostos teóricos e metodológicos da Terminologia, mais especificamente nos da

" Universidade de São Paulo (USP). E-mail: bfcurti@gmail.com.

** Universidade Estadual Paulista (UNESP). E-mail: lidia.barros@unesp.br. TradTerm, São Paulo, v.35, junho/2020, p. 102-116 
Terminologia Diacrônica, e em estudos das áreas do Direito da França e do Brasil, e de História da França e do Brasil. Assim, esperamos contribuir para o desenvolvimento dos estudos diacrônicos em Terminologia, que ainda são raros no Brasil, bem como ampliar o conhecimento linguístico e cultural sobre a matéria.

Palavras-chave: Mariage; Casamento; Terminologia Diacrônica.

Abstract: In the light of a diachronic-comparative perspective, we aim to verify the semantic and conceptual evolution of the terms mariage and casamento in the field of Law regarding the period from the first regulation on official marriages in France (1563) and Brazil (1824) until the unprecedented appearance of civil and secular marriages in the French and Brazilian legislations, respectively in 1791 and 1890. In addition, we intend to relate this evolution to the sociocultural and historical aspects of these countries. To do so, we based this study on the theoretical and methodological assumptions of Terminology, more specifically on Diachronic Terminology, and on research in the areas of French and Brazilian Law and History of France and Brazil.

Keywords: Mariage; Casamento; Diachronic Terminology.

\section{Introdução}

Até o surgimento do casamento civil no contexto jurídico da França e do Brasil, os casamentos religiosos eram considerados casamentos válidos em ambos os países. Na França, a Revolução Francesa (1789-1799) trouxe vários ideais, dentre os quais destacamos o princípio da laicização do Estado que resultou na instituição do casamento civil em 1791. Cerca de cem anos depois, no Brasil, a Proclamação da República (1889) também possibilitou, dentre outros fatores, a separação entre Estado e Igreja e, consequentemente, a instauração do casamento civil nesse país em 1890.

Considerando esses fatos, propomo-nos a investigar, à luz de uma perspectiva diacrônico-comparada, a evolução semântico-conceitual dos termos mariage e casamento no domínio do Direito desde a primeira regulamentação dos casamentos na França (1563) e no Brasil (1827) até o aparecimento inédito do conceito de casamento civil e laico nas legislações francesa e brasileira em 1791 e 1890 respectivamente, relacionando-a aos aspectos socioculturais que subjazem a essas unidades terminológicas. A nosso ver, esses aspectos estão ligados a mudanças nos âmbitos político, social, 
ideológico e cultural vividos de forma particular por esses países em momentos diferentes de sua história.

Para tanto, fundamentamo-nos nos pressupostos teóricos e metodológicos da Terminologia (Cabré [1999], Barros, [2004, 2007] dentre outros), mais especificamente nos da Terminologia Diacrônica (Dury [1999, 2013] e outros). Buscamos ainda uma bibliografia especializada no domínio de História da França e do Direito francês, e de História do Brasil e do Direito brasileiro a fim de explicar o porquê de esses termos terem sofrido mudanças no nível semântico-conceitual e quais semelhanças e diferenças podem ser estabelecidas entre essas transformações. Assim, observamos essa evolução ao longo do tempo e sua relação com as principais mudanças socioculturais e históricas que aconteceram nesses países entre os séculos XVI e XIX.

Este artigo está organizado da seguinte forma: primeiramente, apresentamos os pressupostos teóricos e metodológicos adotados e explicamos o processo de formação dos corpora de estudo e de análise dos dados; em seguida, expomos os resultados alcançados; e, por fim, apresentamos algumas considerações finais seguidas pelas referências deste trabalho ${ }^{1}$.

\section{Aspectos teóricos e metodológicos adotados}

A Teoria Comunicativa da Terminologia (TCT), sistematizada por Cabré (1999), possibilita-nos compreender que o estatuto de termo é atribuído a uma unidade lexical graças às condições pragmáticas que visam adequá-la a um determinado tipo de comunicação (CABRÉ 1999). Assim, o termo pode ser considerado uma unidade linguística, cuja expressão e cujo conteúdo são inseparáveis (signo linguístico/unidade linguística). É, portanto, “uma unidade lexical com um conteúdo específico dentro de um domínio especializado" (BARROS 2004: 40).

No que concerne ao plano do conteúdo, o termo denomina um conceito, que, por sua vez, é entendido, no âmbito deste trabalho, como “uma unidade de pensamento constituída por abstração com base em

\footnotetext{
1 Este trabalho foi financiado pela Fundação de Amparo à Pesquisa do Estado de São Paulo (FAPESP), à qual agradecemos pelo apoio concedido.
}

TradTerm, São Paulo, v.35, junho/2020, p. 102-116

www.revistas.usp.br/tradterm 
características, traços, atributos ou propriedades comuns a uma classe de objetos, de relações ou de entidades” (BARROs 2007: 37).

Além disso, a TCT entende que o termo pertence à língua e, sendo assim, está sujeito a sofrer interferências e influências diversas, já que a língua não é nem homogênea e nem estática. 0 mesmo acontece com o léxico de uma área de especialidade, uma vez que esse pertence à língua geral. Dessa forma, a dinamicidade também the é intrínseca (ALVES 2006).

Ao considerarmos que o léxico das línguas em geral é dinâmico, pois se transforma e se enriquece constantemente, as linguagens de especialidade, enquanto subsistemas linguísticos, não escapam desse processo (BARROS 1998). Essa dinâmica de produção lexical resulta, principalmente, “de uma necessidade de nomeação ou de um fato social, que, em um momento da história da sociedade, determina a criação de uma nova unidade lexical” (ALVES 2009: 1821).

Nesse sentido, novos termos podem surgir e/ou unidades terminológicas que já existem podem mudar juntamente com a língua que evolui no contexto de transformações sociais e culturais da comunidade que a fala. Desse modo, as unidades lexicais (sendo termos ou não), por serem influenciadas por diferentes períodos e concepções históricas, podem sofrer transformações e renovações nos níveis morfológico, sintático e semântico (BORTOLATO 2013).

A Terminologia Diacrônica se preocupa, então, em estudar a evolução das unidades terminológicas nesses níveis. Mais especificamente com relação à evolução semântico-conceitual dos termos, a qual nos interessa particularmente neste trabalho, essa vertente contribui com um ponto de vista histórico sobre os conceitos (DURY 1999).

A variação semântico-conceitual de um termo ao longo do tempo acontece principalmente porque os conceitos são unidades de conhecimento que acompanham os progressos de determinada área do saber, os quais estabelecem novos traços conceituais que modificam ou tornam os conceitos mais específicos (CONCEIÇÃo 1999). Há, portanto, uma relação entre a evolução dos conhecimentos dos domínios de especialidade e a variação (ou evolução) dos conceitos que se referem a esses conhecimentos. 
O estudo diacrônico, tal como o que propomos neste artigo, pode, então, evidenciar fenômenos ligados à evolução dos conhecimentos, dos conceitos e das unidades terminológicas que os denominam (DURY 2013). É, portanto, à luz dessa perspectiva que realizamos um estudo sobre a evolução dos conceitos denominados pelos termos mariage e casamento a partir do momento em que ocorreu a primeira regulamentação sobre o registro oficial dos casamentos para fins de controle do Estado (em 1563, na França, e em 1827, no Brasil) até a instituição do casamento civil nesses dois países (em 1791 e em 1890, respectivamente). Em nossas buscas, verificamos que há três leis publicadas nesse período que modificaram diferentes aspectos sobre os casamentos oficiais nesses países e que podem ter levado esses termos a sofrerem uma evolução semântico-conceitual nesse período.

Assim, formamos quatro corpora de estudo: 1) o LFCorpus, composto por três documentos legais franceses publicados em 1563, 1787 e 1791; 2) o LBCorpus, que contém três documentos legais datados de 1827, 1861 e 1890; 3) o Corpus de Apoio-FR, composto por uma bibliografia especializada em História da França e Direito francês; e 4) o Corpus de Apoio-BR, que reúne publicações especializadas em História do Brasil e Direito brasileiro.

Após a constituição dos corpora, analisamos o LFCorpus e o LBCorpus a fim de verificar as mudanças legislativas sobre os casamentos oficiais na França e no Brasil. Com base nas alterações encontradas, delimitamos os conceitos denominados pelos termos mariage e casamento no domínio do Direito. Em seguida, buscamos uma bibliografia especializada no assunto, a qual compôs os corpora de apoio em francês e em português, com o intuito de explicar as mudanças conceituais encontradas, relacionando nossas explicações a aspectos socioculturais, políticos, ideológicos e históricos da França e do Brasil entre os séculos XVI e XIX. Por fim, comparamos os resultados.

\section{Evolução semântica dos termos mariage e}

\section{casamento}

TradTerm, São Paulo, v.35, junho/2020, p. 102-116

www.revistas.usp.br/tradterm 
Nesta seção, apresentamos os resultados de nosso estudo diacrônicocomparado sobre a evolução semântico-conceitual desses termos no domínio do Direito partindo do momento em que leis estabeleceram a prerrogativa dos registros matrimoniais para fins de controle até o surgimento do conceito de casamento civil e laico na legislação da França e do Brasil.

Para tanto, dividimos nossas análises em três partes: a primeira se refere ao estudo da evolução semântico-conceitual do termo mariage; a segunda diz respeito à evolução semântico-conceitual do termo casamento, e a terceira expõe nosso estudo comparativo sobre a evolução dessas duas unidades terminológicas nesse contexto.

\subsection{Evolução semântica de mariage}

Durante o século XVI, a França passou por um período de conflitos entre católicos e protestantes (CURTl; BARROS 2016). Em resposta a essa situação, a Igreja Católica realizou o Concílio de Trento (1545-1563) que fez uma revisão completa de seus doutrinamentos (LAROUSSE 2015). Dentre as propostas desse Concílio, destacamos o decreto Tametsi (1563) que regulamentou a celebração dos casamentos católicos (BARIPEDIA 2015). A partir desse momento,

(...) os padres foram incumbidos de registrar os casamentos dos católicos. Até essa época, o casamento era o resultado de em um simples acordo entre os noivos [durante o qual o] padre estava presente como testemunha e [cuja] cerimônia não acontecia obrigatoriamente na igreja; não estava em questão considerar o casamento como um sacramento. ${ }^{2}$ (HOUDAILLE; BoloGNE 1999: 820)

A Igreja Católica passou, então, a controlar efetivamente (e legalmente) os casamentos a fim de "proibir" a celebração das uniões clandestinas, ou seja, não católicas (D’ALMÉRAS 1903). Desse modo, até 1787, o casamento católico era a única possibilidade de união oficial entre um homem

\footnotetext{
${ }^{2}$ No original: (...) les curés furent tenus d'enregistrer les mariages des catholiques. Jusqu'à cette époque le mariage résultait d'un simple accord entre les fiancés. Le prêtre y assistait à titre de témoin et la cérémonie ne se déroulait pas obligatoirement à l'église; il n'était pas question de considérer le mariage comme un sacrement.
}

TradTerm, São Paulo, v.35, junho/2020, p. 102-116

www.revistas.usp.br/tradterm 
e uma mulher aos olhos da monarquia uma vez que a religião oficial da França era a católica. Consequentemente, somente aqueles que professassem essa religião poderiam se casar legalmente nesse país.

Considerando esses fatos, entendemos que o termo mariage denominava, no contexto jurídico-monárquico francês, o conceito específico de união católica e indissolúvel entre um homem e uma mulher oficialmente reconhecida pela Monarquia francesa que poderia ser rompida pela separação .

Desde o século XVIII, principalmente após o ano de 1760 , as igrejas protestantes foram reconstruídas e esse fato possibilitou o aumento do número de "não católicos" que não tinham seu estado civil reconhecido pelo reino francês (VILLARD 1988). Para solucionar essa situação, o rei, por meio do Édito de Versalhes de 1787, reconheceu os efeitos civis dos nascimentos, dos casamentos e dos falecimentos de quem seguia uma religião diferente da religião oficial (católica) (CAPÍTULO I - FRANÇA 1787).

Dessa forma, esse édito tornou possível o registro civil dos casamentos religiosos que, a partir desse momento, passaram a ser aceitos pela Monarquia. Com essa mudança, observamos que a unidade terminológica mariage foi alterada do ponto de vista semântico e passou a denominar o conceito de união religiosa e indissolúvel entre um homem e uma mulher oficialmente reconhecida pela Monarquia francesa que poderia ser rompida pela separação.

Entre os anos de 1789 a 1799, a França viveu o período da Revolução Francesa, durante o qual a República foi implantada e a separação entre Estado e Igreja foi reconhecida, já que esse movimento defendia fortemente a laicização da nação. Por conseguinte, o casamento como contrato civil foi instituído pela primeira vez em 1791. Assim, a lei republicana passou a considerar

\footnotetext{
${ }^{3}$ Diferentemente do divórcio, a séparation de corps "existia no Direito antigo francês, que a trouxe do Direito Canônico" (BARBIN, S/d., tradução nossa) ${ }^{3}$. Após o Concílio de Trento, essa separação "foi o único remédio que os católicos podiam usar para curar seus infortúnios conjugais" (Coulon 1890: 137, tradução nossa). Assim, ela possibilitava a ruptura (ou seja, o rompimento) do vínculo conjugal sem dissolvê-lo e, portanto, os esposos separados não podiam contrair novas núpcias. Essa separação era conhecida como séparation des catholiques (BARBIN S/d.).
}

TradTerm, São Paulo, v.35, junho/2020, p. 102-116

www. revistas.usp.br/tradterm 
(...) o casamento como contrato civil. - O Poder Legislativo estabelecerá para todos os habitantes, sem distinção, o modo segundo o qual os nascimentos, os casamentos e os óbitos serão registrados; e designará os oficiais públicos que receberão e conservarão as certidões (ARTIGO 7 - FRANÇA $1791)^{4}$.

Assim, com base na Constituição Republicana francesa, entendemos que o termo mariage sofreu uma variação semântico-conceitual. A partir de então, essa unidade terminológica passou a denominar o conceito de união laica, civil $e^{\text {indissolúvel }}{ }^{5}$ entre um homem e uma mulher reconhecida pela República francesa que poderia ser rompida pela separação.

\subsection{Evolução semântica de casamento}

O Brasil, assim como a França, passou por diferentes regimes de governo que também influenciaram, de forma mais específica, o conceito jurídico de casamento. Durante o período colonial (1500-1822), o Brasil seguia as Ordenações Portuguesas em matéria de organização matrimonial (SIMÕES 2018). Assim sendo, os casamentos eram controlados pela Igreja Católica e fundamentados no Concílio de Trento, uma vez que a religião oficial da metrópole (e consequentemente da colônia) era a católica.

Essa realidade se manteve até os tempos de Império (1822-1889), quando o Brasil se tornou independente de Portugal. Em 1824, a primeira Constituição Imperial brasileira determinou que a religião católica se tornasse a religião oficial do Império, mas não tratou, de forma específica, dos registros dos casamentos brasileiros (ARTIGO 5 - BRASIL 1824).

Em 1827, um decreto baseado no Direito canônico foi criado para estabelecer a obrigatoriedade de aplicação das determinações do Concílio de Trento e da Constituição do Arcebispado da Bahia, oficializando, assim, a influência católica na organização dos matrimônios no Brasil (BRASIL 1827;

\footnotetext{
${ }^{4}$ No original: (...) le mariage que comme contrat civil. - Le Pouvoir législatif établira pour tous les habitants, sans distinction, le mode par lequel les naissances, mariages et décès seront constatés ; et il désignera les officiers publics qui en recevront et conserveront les actes.

${ }^{5}$ É importante dizer que o divórcio foi instituído no ano seguinte à instituição do casamento civil na França (França 1989).
}

TradTerm, São Paulo, v.35, junho/2020, p. 102-116

www.revistas.usp.br/tradterm 
VIEIRA; Gomes 2015). Desse modo, os casamentos, os nascimentos e os óbitos deveriam ser registrados pelas paróquias e somente aqueles que professassem a religião católica tinham o direito de ser registrados.

Com base nesses dados, entendemos que, no contexto jurídico-imperial brasileiro, o termo casamento denominava o conceito de uniáo católica $e$ indissolúvel entre um homem e uma mulher oficialmente reconhecida pelo Império brasileiro.

Uma vez que os casamentos oficiais continuavam restritos aos seguidores da religião católica, as uniões matrimoniais celebradas por outras instituições religiosas não eram legalmente reconhecidas (SOARES 1895). Assim, embora essas uniões existissem no Brasil do século XIX, o conceito do termo casamento (enquanto união oficial) não contemplava os traços semânticos referentes a outras religiões.

Nos anos que sucederam o decreto de 1827, muito se discutiu a respeito da secularização do casamento como forma de atrair imigrantes e de legitimar as uniões entre não católicos nesse país (SOARES 1895; CURTI \& BARROS 2018). Diante dessa nova realidade, o Imperador estendeu os efeitos civis aos casamentos não católicos em 1861 e seu registro passou a ser regulado pelo Império (ARTIGOS 1 E 2 - BRASIL 1861). Assim, nossas análises nos revelaram que esse decreto alterou o conceito do termo casamento, que passou a denominar a união religiosa e indissolúvel entre um homem e uma mulher, católicos ou não, que era oficialmente reconhecida pelo Império brasileiro e que não poderia nem ser rompida e nem dissolvida de forma legal.

Após a Proclamação da República em 1889, houve a separação entre Igreja e Estado e, consequentemente, o Brasil se tornou uma nação laica. Dessa forma, em 1890, o Governo Interino do Brasil instaurou o casamento civil e laico por meio do Decreto $N^{\circ} 181$ (BRASIL 1890). De acordo com esse decreto, o casamento tornava-se um ato laico e legal de uma união legítima e indissolúvel entre um homem e uma mulher com o propósito de procriação e construção da família, outorgando-lhes direitos e responsabilidades específicos (CAPÍtULO VII - BRASIL 1890).

Desse modo, os casamentos religiosos passaram a ser opcionais, visto que não eram mais oficiais segundo a legislação brasileira. Nesse contexto TradTerm, São Paulo, v.35, junho/2020, p. 102-116

www.revistas.usp.br/tradterm 
jurídico-republicano, verificamos que o termo casamento sofreu uma importante alteração semântico-conceitual, uma vez que os traços semânticos referentes às religiões foram substituídos pelo caráter laico do Estado. Assim, essa unidade terminológica passou a denominar o conceito de única possibilidade de união civil, laica e indissolúvel entre um homem e uma mulher, atribuindo-lhes direitos e deveres específicos na manutenção do casamento sob direção do marido, que poderia ser rompida pelo divórció6.

\subsection{A evolução semântica de mariage e casamento: semelhanças e diferenças}

Com base neste estudo, pudemos observar algumas semelhanças e diferenças entre a evolução dos conceitos denominados pelos termos mariage e casamento ao longo da história das legislações francesa e brasileira até a instituição do casamento civil e laico nesses dois países. Nesse sentido, verificamos que, na França, apenas os católicos podiam se casar até 1787, ano em que a Monarquia concedeu a possibilidade aos não católicos de se casarem legalmente nesse país, visto que o número de igrejas protestantes e de seus seguidores aumentava cada vez mais.

No Brasil, o Império reconheceu os efeitos civis dos casamentos não católicos por meio do Decreto $n^{\circ} 1.144$ de 1861. Esse decreto decorreu, principalmente, da necessidade de regularização dos nascimentos, dos casamentos e dos óbitos de todos os cidadãos para controle do Estado. Assim, os termos casamento e mariage só se aproximaram do ponto de vista semântico-conceitual em 1861. Nesse sentido, verifica-se um ritmo diferente entre as duas sociedades, na medida em que o Brasil só modificou sua lei em relação aos casamentos não católicos 74 anos depois da França.

Além disso, na França, os casamentos oficiais, que eram apenas religiosos até 1791 , poderiam ser legalmente rompidos pela separação (não divórcio), ou seja, o casal poderia se separar legalmente, mas não poderia se

\footnotetext{
${ }^{6}$ Esse tipo de divórcio era diferente do divórcio que conhecemos hoje. Ele determinava que o casal podia se separar legalmente, mas estava impedido de contrair novas núpcias (CURTICONTESSOTO; BARROS 2018).
}

TradTerm, São Paulo, v.35, junho/2020, p. 102-116

www.revistas.usp.br/tradterm 
casar novamente. No entanto, essa possibilidade de rompimento legal do casamento não existia no contexto jurídico brasileiro até 1890 , quando foram instituídos o casamento civil e o divórcio (equivalente ao desquite ou separação) no Brasil. Assim sendo, há outra diferença, de natureza conceitual, entre os termos mariage e casamento antes da instituição do casamento civil nesses dois países.

Com relação a esse ponto, o casamento civil foi instituído, na França, em 1791 em decorrência da instauração da República e da separação entre Estado e Igreja no contexto da Revolução Francesa (1789-1799). Essa distância entre casamentos civis e casamentos religiosos é um aspecto cultural não só desse país, mas também de outras nações do Ocidente. Aliás, a maior parte delas se espelharam nessa postura da França (CURTI; BARRos 2016). Esse foi o caso do Brasil cem anos depois em um contexto governamental e social diferente.

Após a instauração da República nos dois países, ambas as legislações instituíram o divórcio. No entanto, o divórcio francês (1792) estabeleceu que os casamentos civis poderiam ser legalmente dissolvidos e, assim, o casal poderia contrair novas núpcias. Em contrapartida, o divórcio brasileiro (1890) determinou que os casamentos civis poderiam ser legalmente rompidos, mas não dissolvidos, ou seja, os ex-cônjuges não podiam se casar novamente de forma legal no Brasil nessa época7.

\section{Considerações finais}

Como vimos, a legislação referente aos casamentos mudou ao longo da história da França e do Brasil. Com base em nossas análises, observamos que essas transformações legislativas influenciaram, de modo mais específico, as unidades terminológicas mariage e casamento e seus conceitos segundo as particularidades de cada país.

\footnotetext{
${ }^{7}$ Atualmente, cônjuges divorciados podem casar de novo do ponto de vista legal. Isso porque, “em 1977, o termo divórcio foi retomado pela Lei $n^{\circ}$ 6.515, porém com nova configuração semântica: agora, a sociedade conjugal poderia ser dissolvida, possibilitando aos cônjuges contraírem novas núpcias" (CURTI; BARROS 2018: 9).
}

TradTerm, São Paulo, v.35, junho/2020, p. 102-116

www.revistas.usp.br/tradterm 
Assim, verificamos que, embora a evolução semântica desses termos apresente traços comuns entre si, ela é marcada, principalmente, por aspectos diferentes. Nesse sentido, essa evolução é um reflexo das transformações nos âmbitos político, social e ideológico pelas quais esses dois países passaram ao longo de sua história.

É importante dizer que os resultados deste trabalho contribuem com o desenvolvimento da área da Terminologia Diacrônica, que ainda é pouco explorada sobretudo no Brasil. Desse modo, esperamos que este estudo possa fomentar investigações que abordem a perspectiva diacrônica em Terminologia em nosso país. Isso porque um número maior de estudos terminológicos diacrônicos aumentaria o conhecimento sobre o potencial evolutivo das estruturas terminológicas, o que poderia ser de interesse de quem ensina as linguagens de especialidade, de tradutores, de terminógrafos ou lexicógrafos, de neólogos, dentre outros (MøLLER 1998: 452).

Além disso, trata-se de uma pesquisa interdisciplinar, que relaciona especialmente as áreas da Linguística, do Direito e da História, e que contribui com a ampliação do conhecimento linguístico e cultural sobre a matéria. 


\section{Referências}

Alves, I. M. A renovação lexical nos domínios de especialidade. Ciência e Cultura. Campinas, v. 58, n. 2, 2006, p. 32-34. Disponível em: <http://cienciaecultura.bvs.br/pdf/cic/v58n2/a13v58n2.pdf>. Acesso em: 10 mar. 2016.

ALVES, I. M. Neologia e implicações textuais. Anais do VI Congresso Internacional da ABRALIN. João Pessoa: Idéia, 2009, pp. 1821-1825. Disponível em: <http://www.leffa.pro.br/tela4/Textos/Textos/Anais/ABRALIN_2009/ PDF/leda\%20Maria\%20Alves\%20-\%20ok.pdf>. Acesso em: 05 nov. 2019.

BARBIN, J. SÉPARATION DE CORPS. Encyclopædia Universalis. BoulogneBillancourt, S/d. Disponível em:

<http://www.universalis.fr/encyclopedie/separation-de-corps/>. Acesso em: 21 nov. 2018.

BARIPEDIA. Décret Tametsi - 1563, online, 2015. Disponível em: <https://baripedia.org/wiki/D\%C3\%A9cret_Tametsi_-_1563>. Acesso em 11 Fev. 2019.

BARROS, L. A. Aspects de la productivité lexicale dans le domaine des espaces protégés du Brésil : la variation orthographique, morphologique et syntaxique. Acta Semiotica et Linguistica, São Paulo, v. 7, 1998, p. 45-86.

Barros, L. A. Curso Básico de Terminologia. São Paulo: Editora da Universidade de São Paulo, 2004.

BARROS, L. A. Conhecimentos de terminologia geral para a prática tradutória. São José do Rio Preto: NovaGraf, 2007.

BORTOLATO, C. P. Uma proposta de tradução da terminologia jurídica do Ancien Régime presente na peça Les Plaideurs de Jean Racine. Dissertação (Mestrado em Letras) - Faculdade de Filosofia, Letras e Ciências Humanas, Universidade de São Paulo, São Paulo, 2013. Disponível em: <http://www.teses. usp.br/teses/disponiveis/8/8146/tde-18112013131108/publico/2013_CarolinaPoppiBortolato_VCorr.pdf>. Acesso em: 27 de Abr. 2016.

BRASIL. Constituição Política do Império do Brazil, 1824. Disponível em: <http://www.planalto.gov.br/ccivil_03/Constituicao/Constituicao24.h tm>. Acesso em: 2 Fev. 2016.

BRASIL. Decreto de 3 de novembro de 1827, 1827. Disponível em: <http://www2.camara.leg.br/legin/fed/decret_sn/18241899/decreto-38408-3-novembro-1827-566712-publicacaooriginal90232-pl.html>. Acesso em: 24 abr. 2016.

TradTerm, São Paulo, v.35, junho/2020, p. 102-116 www.revistas.usp.br/tradterm 
BRASIL. Decreto $N^{\circ} 1.144$, de 11 de setembro de 1861, 1861. Disponível em: <http: / /www2.camara.leg.br/legin/fed/decret/1824-1899/decreto1144-11-setembro-1861-555517-publicacaooriginal-74767-pl.html>. Acesso em: 24 Abr. 2016.

BRASIL. Decreto $N^{\circ} 181$, de 24 de janeiro de 1890: Marechal Deodoro da Fonseca promulga a lei sobre o casamento civil, 1890. Disponível em: <http://www.planalto.gov.br/ccivil_03/decreto/18511899/D181.htm>. Acesso em: 10 Abr. 2015.

CABRÉ, M. T. La terminología: representación y comunicación. Elementos para una teoría de base comunicativa y otros artículos. Barcelona: IULA, 1999.

CONCEIÇão, M. C. Terminologie et transmission du savoir: (re)construction(s) de concepts. In: Delavigne, V.; Bouveret, M. (Org.), Sémantique des termes spécialisés. Rouen: Presses Universitaires de Rouen, 1999. p. 33-42.

Coulon, H. Le divorce et la séparation du corps. Paris: Marchal et Billard, 1890.

CURTI, B.; BARRos, L. A. Um estudo da evolução semântica do termo "casamento" no domínio jurídico brasileiro à luz da Terminologia Diacrônica. In: Alves, I. M.; GANANÇA, J. H. L. (Org.), Os estudos lexicais em diferentes perspectivas. São Paulo: FFLCH/USP, v. 7, 2018. p. 82-96.

CuRti-Contessoto, B.; BarRos, L. A. Termos denominativos dos conceitos de rompimento e de dissolução do casamento na história do Brasil. Revista Digital Internacional de Lexicología, Lexicografía y Terminología (ReDILLeT), Córdoba, v. 1, n.1, 2018, p. 72-85.

CURTI, B. F.; BARROS, L. A terminologia referente ao local de expedição das certidões de casamento francesas: um olhar sobre seus aspectos socioculturais. Domínios de Lingu@Gem, Uberlândia, v. 10, n. 3, 2016, p. 834-850.

D’Almeras, H. Le mariage chez tous les peuples. Paris: Schleicher, 1903.

DURY, P. Étude comparative et diachronique des concepts ecosystem et écosystème. Meta : journal des traducteurs / Meta: Translators' Journal, Montréal, v. 44, n. 3, 1999, p. 485-499.

DURY, P. Que montre l'étude de la variation d'une terminologie dans le temps. Quelques pistes de réflexion appliquées au domaine médical. Debate Terminológico, Ivoti, n. 9, 2013, p. 2-10. Disponível em: <https://seer.ufrgs.br/riterm/article/view/37168/24030>. Acesso em: 19 set. 2019. 
FrançA. Édit de Versailles,7 novembre, 1787. Disponível em: <http://huguenotsweb.free.fr/histoire/edit1787.htm>. Acesso em: 23 de janeiro de 2019.

França. Constitution de 1791. Paris : Conseil Constitutionnel, 1791. Disponível em: <https://www.conseil-constitutionnel.fr/les-constitutions-dans-lhistoire/constitution-de-1791>. Acesso em: 5 Nov. 2018.

FrançA. Loi du 20 Septembre 1792 sur les causes, le mode et les effets du divorce. In: Population \& Société. Paris: INED, 1989.

Houdaille, J. ; Bologne, J.-C. Histoire du mariage en Occident. Population, n. 4/-5, 1999, pp. 820-821. Disponível em: <http://www.persee.fr/web/revues/home/prescript/article/pop_003 2-4663_1999_num_54_4_7050>. Acesso em: 16 Ago. 2016.

LAROUSSE. Encyclopédie Larousse en ligne : Concile de Trente. [Online]. 2015. Disponível em:

<http://www.larousse.fr/encyclopedie/divers/concile_de_Trente/147 379>. Acesso em: 9 set. 2015.

MølleR, B. A la recherche d'une terminochronie. Meta: journal des traducteurs / Meta: Translators' Journal, Montréal , v. 43, n. 3, 1998, p. 426-438. Disponível em:

<https: //www.erudit.org/revue/meta/1998/v43/n3/003655ar.pdf>. Acesso em: 10 mar. 2016.

OBEID, R. I. Notas sobre as origens do casamento civil no Brasil. JusNavigandi [Online], 2013. Disponível em: <https://jus.com.br/artigos/23332>. Acesso em: 19 jun. 2017.

SILVA, P. J. DA. A Igreja Católica e as relações políticas com o Estado na Era Vargas. Anais dos Simpósios da ABHR [Online], 2012. Disponível em: <http://www.abhr.org.br/plura/ojs/index.php/anais/article/viewFile /456/391>. Acesso em: 1 abr. 2016.

SoARES, O. DE M. Casamento civil - Decreto n. 181 de 14 de janeiro de 1890: commentado e annotado. Rio de Janeiro: H. Garnier, 1895.

VILLARD, M. Documents : L'Edit de Tolérance vu par un parlementaire aixois. Revue Provence historique, v. 38, n. 154 , 1988, p. 465-468.

Recebido em: 15/04/2019

Aceito em: 29/05/2020

Publicado em junho de 2020 